\title{
Inaccuracies introduced by single width blood pressure cuffs
}

\author{
Jeffrey C Andrews, Blake DeWitt, Terry E Czerwien, Miro Bijelic and Neal S Latman
}

Blood pressure cuff dimensions directly affect accuracy of blood pressure measurements. For accurate blood pressure measurements, the width of the cuff must be proportional to arm circumference. A cuff that is too narrow results in falsely high blood pressure values, and a cuff that is too wide results in falsely low values. Some blood pressure standards permit a single width cuff regardless of arm circumference. The purpose of this study was to evaluate whether $12 \mathrm{~cm}$ single width cuffs currently permitted by the British Hypertension Society (BHS) standard are sufficiently accurate to pass the Association for the Advancement of Medical Instrumentation (AAMI), BHS, and European Society of Hypertension (ESH) International Protocol (IP1) Working Group standards for accuracy. Each of 101 subjects was tested sequentially with both a single and a proportional width cuff in random order. Auscultatory blood pressure was determined by 2 observers using a double binaural stethoscope. Accuracy was determined by comparing the resulting differences with the AAMI, BHS, and IP1 standards for accuracy. The single width blood pressure cuff failed the AAMI accuracy standards for both systolic blood pressure on large arms and diastolic blood pressure on small and large arms, and overall. The single width cuffs, also, failed the BHS accuracy standards for diastolic BP. In conclusion, these single width cuffs could result in a significant number of people being misdiagnosed and mistreated for hypertension. Therefore, to avoid 'cuff hypertension' and 'cuff hypotension', the cuff width should be proportional to arm circumference.

Hypertension Research (2011) 34, 209-211; doi:10.1038/hr.2010.210; published online 4 November 2010

Keywords: accuracy; blood pressure; blood pressure standards; hypotension

\section{INTRODUCTION}

Ever since blood pressure was first accepted as an important consideration in medicine, efforts have been made to make an accurate, indirect means of measuring it. Many credit the start of the modern era of blood pressure measurement with Scipione Riva-Rocci when, in 1896, he first used a $5 \mathrm{~cm}$ wide inflatable cuff to occlude the brachial artery. ${ }^{1,2}$ Five years later, Friedrich von Recklinghausen noted that a $5 \mathrm{~cm}$ wide cuff was highly inaccurate, and recommended increasing the width to $10-12 \mathrm{~cm} .{ }^{3,4}$ In 1905 , Nicolai Sergeivich Korotkoff made his famous contribution to blood pressure study when he described how to determine systolic and diastolic blood pressure by listening to the characteristic sounds that bear his name. ${ }^{1}$ This opened the doors to further studies to determine the attributes of the optimal cuff.

As von Recklinghausen demonstrated, the dimensions of the cuff directly affect the blood pressure measurement. ${ }^{3,4}$ Multiple studies have found that the use of a cuff that is too narrow will give erroneously high blood pressure values, and that too wide a cuff will give falsely low blood pressure values. ${ }^{2,3,5-7}$ According to Geddes, the most accurate and appropriate cuff width and length is dependent on 'age, weight, height, and upper arm circumference.' 3 Geddes also pointed out that the optimum cuff width for measuring systolic blood pressure is different from that for diastolic BP. ${ }^{3}$
As it is clearly impractical to have custom fitted cuffs for every patient, a variety of recommendations have been made in an attempt to balance the need for accurate instrumentation with both convenience and the realities of manufacturing. ${ }^{2,7}$ At the end of the spectrum where accuracy reigns, Geddes states that cuff width should be $40 \%$ of the upper arm circumference. ${ }^{3}$ At the other end, there are advocates for a single width cuff for all adults. ${ }^{4}$ Many of the factors involved with blood pressure measurement including the cuff have been reviewed by O'Brien, et al. ${ }^{7}$

Every recommendation falls somewhere on the spectrum of accuracy vs. convenience. The Association for the Advancement of Medical Instrumentation (AAMI) standard explicitly permits a cuff with a width of $40 \%$ of the upper arm, and allows deviations from this only if data is provided that proves its accuracy. ${ }^{8}$ The British Hypertension Society (BHS) standard allows for a single width cuff of $12 \mathrm{~cm}$ and of varying length. ${ }^{4}$ The European Society of Hypertension (ESH) International Protocol (IP1) Working Group leaves the decision to the manufacturers. ${ }^{9}$ The American Heart Association recommends four cuff sizes that are designed to cover $46 \%$ of the upper arm circumference except where an excessive width would result in an unusable cuff. ${ }^{10}$

The purpose of this project was to evaluate whether $12 \mathrm{~cm}$ single width cuffs currently on the market are accurate enough to replace proportional width cuffs. 


\section{METHODS}

A total of 101 subjects were recruited for this study as a sample of convenience. Two sequential blood pressure measurements from each subject were concurrently and independently obtained by two observers. This resulted in a total of 202 paired measurements, or 404 total measurements. Every subject gave written informed consent, and the study was approved by the Institutional Review Board of West Texas A\&M University.

Subjects were instructed to stay relaxed, and to remain quiet while their blood pressure was recorded. ${ }^{7}$ One of their upper arms was measured in order to determine the appropriate cuff size recommended by the manufacturers as listed in Table 1 for both the proportional and single width cuffs. An initial palpatory systolic blood pressure measurement was performed on each subject and was followed by two auscultatory measurements. For both of these measurements, the recommended proportional or single width cuff was fitted and inflated to approximately $20 \mathrm{~mm} \mathrm{Hg}$ higher than the palpatory measure. A double binaural stethoscope was used, and a paired observation was made. The order of the two auscultatory measurements was randomized to minimize differences that might arise due to the order of sequential readings. Approximately 3 min were given as a resting period between each sequential reading in order to re-equilibrate the subject's BP.

The calibrations of the aneroid sphygmomanometers used in the study were verified against a mercury manometer at the beginning and end of the study to ensure accuracy. 6,7

Table 1 Manufacturer-recommended cuff sizes

\begin{tabular}{lcc}
\hline Cuff style & $\begin{array}{c}\text { Upper arm circumference } \\
\text { (inches) }\end{array}$ & $\begin{array}{c}\text { Recommended cuff } \\
\text { size }(\mathrm{cm}) \text { (Label) }\end{array}$ \\
\hline Proportional width & $7-10.75$ & $9 \times 17.5$ (Child) \\
& $10.75-15.75$ & $12 \times 22$ (Adult) \\
Single width & $13.25-19.5$ & $15 \times 31$ (Large) \\
& $8.6-11.75$ & $12 \times 23.5$ (Small adult) \\
& $11.75-16.5$ & $12 \times 33$ (Adult) \\
& $16.5-18.8$ & $12 \times 38.5$ (Large adult) \\
\hline
\end{tabular}

aWidth $\times$ Length.

Table 2 Demographics $(N=101)$

\begin{tabular}{lccc}
\hline Characteristic & Minimum-maximum & Mean & Median \\
\hline Age & $18-85$ years & 35 years & 23 years \\
Upper arm circumference & $8.5-17.25$ inches & 12.12 inches & 11.75 inches \\
Pulse & $50-98$ beats per min 71 beats $/$ minute & 71 beats $/$ minute \\
Systolic BP & $90-162 \mathrm{~mm} \mathrm{Hg}$ & $122 \mathrm{~mm} \mathrm{Hg}$ & $121 \mathrm{~mm} \mathrm{Hg}$ \\
Diastolic BP & $60-106 \mathrm{~mm} \mathrm{Hg}$ & $80 \mathrm{~mm} \mathrm{Hg}$ & $80 \mathrm{~mm} \mathrm{Hg}$ \\
\hline
\end{tabular}

Abbreviation: BP, blood pressure.
All statistical analysis was performed using Microsoft Excel 2002 and StatGraphics Centurion XV. This included ranges, means, medians, mean differences, and standard deviations.

\section{RESULTS}

As shown in Table 2, there was a wide range of demographic characteristics. Of the 101 subjects, there were 57 males and 44 females. The 'child' cuff $(9 \times 17.5 \mathrm{~cm})$ was required by 23 subjects, 70 needed the 'adult' cuff $(12 \times 22 \mathrm{~cm})$, and 8 used the 'large' cuff $(15 \times 31 \mathrm{~cm})$ as indicated by the cuff manufacturers.

Reliability of simultaneous measurements of the two observers was within the AAMI standard for accuracy. The mean systolic blood pressure difference between observers was $1.4 \mathrm{~mm} \mathrm{Hg}$ ( \pm 1.1 s.d.). The mean diastolic blood pressure reliability was $1.2 \mathrm{~mm} \mathrm{Hg}$ ( \pm 1.1 s.d.). The reliability was well within the AAMI accuracy standard requirements with $95 \%$ of systolic and $98 \%$ of diastolic paired blood pressure measurements within $0-2 \mathrm{~mm} \mathrm{Hg}$ difference.

The AAMI standard for accuracy is a pass/fail system that compares the mean difference of observations with a set list of acceptable standard deviations. ${ }^{8}$ Table 3 compares the overall accuracy of the $12 \mathrm{~cm}$ single width cuff, and separates that overall accuracy into the three classifications of upper arm circumferences. This illustrates how the performance of the single width cuff in this study was affected by varying upper arm circumferences when compared to the equivalent proportional width cuff. Overall, the $12 \mathrm{~cm}$ single width cuff failed the AAMI accuracy standard because its diastolic standard deviation is greater than AAMI's maximum acceptable deviation. When each $12 \mathrm{~cm}$ single width cuff is compared against its proportional width counterpart, which is closer to the ideal $40-46 \%$, it failed the child diastolic, and both the large adult systolic and diastolic categories. ${ }^{3,10}$

The BHS standard for accuracy is a ranking system that gives a letter grade depending on what percentage of the observations falls within 5, 10 , and $15 \mathrm{~mm} \mathrm{Hg}$ of the accepted value. ${ }^{4}$ Table 4 lists the three letter grades, their requirements, and the overall performance of the single width cuffs. All three conditions must be met or exceeded in order to receive that ranking. Although Table 4 shows that the $12 \mathrm{~cm}$ single width cuffs made a ' $\mathrm{C}$ ' grade according to the BHS accuracy standard due to their low diastolic accuracy, the BHS only recommends the use of devices that score a 'B' or higher. ${ }^{10,11}$

The ESH International Protocol of 2002 (IP1) standard for accuracy is a pass/fail system that requires $50 \%$ of the observations to fall within $5 \mathrm{~mm} \mathrm{Hg}$ of the accepted value. ${ }^{9}$ The $12 \mathrm{~cm}$ single width cuffs passed with $68 \%$ of the systolic and $60 \%$ of the diastolic blood pressure measurements falling within $5 \mathrm{~mm} \mathrm{Hg}$. The new revision of 2010 of the ESH International Protocol (IP2) is scheduled to supersede ESHIP1 from 1st July, 2010. ${ }^{12}$ Based on the ESH-IP2 standard for accuracy,

Table 3 AAMI standard for accuracy of $12 \mathrm{~cm}$ single width cuffs compared with three proportional width cuffs

\begin{tabular}{|c|c|c|c|c|c|c|}
\hline Proportional cuff sizes & $\begin{array}{c}\text { Systolic BP } \\
\text { Observed mean } \\
\text { difference }^{\mathrm{a}}\end{array}$ & $\begin{array}{l}\text { Systolic BP } \\
\text { Observed s.d. }\end{array}$ & $\begin{array}{c}\text { Systolic BP } \\
\text { Maximum acceptable } \\
\text { deviation }^{\mathrm{b}}\end{array}$ & $\begin{array}{c}\text { Diastolic BP } \\
\text { Observed mean } \\
\text { difference }^{c}\end{array}$ & $\begin{array}{l}\text { Diastolic BP } \\
\text { Observed s.d. }\end{array}$ & $\begin{array}{c}\text { Diastolic BP } \\
\text { Maximum acceptable } \\
\text { deviation }^{c}\end{array}$ \\
\hline Overall & 1.49 & 6.21 & 6.87 & 1.84 & $7.87^{d}$ & 6.78 \\
\hline Child cuff $(9 \times 17.5 \mathrm{~cm})$ & 0.65 & 4.21 & 6.93 & 2.57 & $11.26^{\mathrm{d}}$ & 6.47 \\
\hline Adult cuff $(12 \times 22 \mathrm{~cm})$ & 1.49 & 6.49 & 6.87 & 1.52 & 6.59 & 6.78 \\
\hline Large cuff $(15 \times 31 \mathrm{~cm})$ & 3.88 & $8.11^{d}$ & 5.97 & 2.5 & $6.59^{d}$ & 6.47 \\
\hline
\end{tabular}

Abbreviations: AAMI, Association for the Advancement of Medical Instrumentation; BP, blood pressure. ${ }^{a}$ Mean difference between systolic BP measurements with the proportional width and single width cuffs. bMaximal s.d. acceptable to pass the AAMI standard.

cMean difference between diastolic BP measurements with the proportional width and single width cuffs.

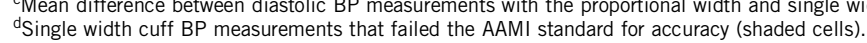


Table 4 BHS standard for accuracy of $12 \mathrm{~cm}$ single width cuffs

\begin{tabular}{|c|c|c|c|c|c|c|}
\hline BHS grade & $\begin{array}{c}\text { Systolic BP } \\
<5 \mathrm{~mm} \mathrm{Hg}(\%)\end{array}$ & $\begin{array}{c}\text { Systolic BP } \\
<10 \mathrm{~mm} \mathrm{Hg}(\%)\end{array}$ & $\begin{array}{c}\text { Systolic BP } \\
<15 \mathrm{~mm} \mathrm{Hg} \mathrm{( \% )}\end{array}$ & $\begin{array}{c}\text { Diastolic BP } \\
<5 \mathrm{~mm} \mathrm{Hg}(\%)\end{array}$ & $\begin{aligned} & \text { Diastolic BP } \\
< & 10 \mathrm{~mm} \mathrm{Hg}(\%)\end{aligned}$ & $\begin{array}{c}\text { Diastolic BP } \\
<15 \mathrm{~mm} \mathrm{Hg}(\%)\end{array}$ \\
\hline$A^{a}$ & 80 & 90 & 95 & 80 & 90 & 95 \\
\hline $\mathrm{C}^{\mathrm{a}}$ & 45 & 75 & 90 & 45 & 75 & 90 \\
\hline Accuracy (grade) ${ }^{b}$ & $68(B)$ & $91(A)$ & $98(A)$ & $60(C)^{c}$ & $86(B)$ & $97(A)$ \\
\hline
\end{tabular}

Abbreviations: BHS, British Hypertension Society; BP, blood pressure.

a Minimum required accuracy to obtain BHS grade. ' $A$ ' or ' $B$ ' grade is required for BHS recommendation.

${ }^{b}$ Accuracy obtained from $12 \mathrm{~cm}$ single width cuffs.

'Failure to pass BHS accuracy standard and obtain recommendation (shaded cell).

the $12 \mathrm{~cm}$ single width cuffs failed Part 1 for diastolic BP and failed Part 2 for systolic and diastolic BP accuracy.

\section{DISCUSSION}

While there is often conflict over the specifics, a general consensus has formed in regard to cuff width; if a cuff is too narrow, the blood pressure will read high, and if the cuff is too wide, the blood pressure will read low. ${ }^{2,3,5-7}$ By definition, a single width cuff will be too narrow for some people, and too wide for others. Unlike proportional width cuffs, single width cuffs are unable to compensate for different arm sizes. As indicated by Table 3, there is a clear trend that errors begin to accumulate as the cuff width deviates from the ideal $40-46 \% .3,10$

This trend is especially worrisome because, as noted by Graves, there is a linked increase in upper arm circumference with the growing obesity in the USA. ${ }^{13}$ It is at these larger arm circumferences that the $12 \mathrm{~cm}$ single width cuffs performed the worst. Since obese individuals are at significantly increased risk of hypertension and cardiovascular disease, it should be evident that blood pressure measurements need to be more accurate rather than less at these arm sizes. As this trend progresses, any single width cuff will increasingly result in inaccurate blood pressure measurements.

Grim has illustrated the effects of this level of error on both the health and financial cost of inaccurate blood pressure measurements in the USA. ${ }^{13}$ According to Grim, if a device is off by $-5 \mathrm{~mm} \mathrm{Hg}$ at the hypertensive cutoff range, it could miss 21 million diagnoses of hypertension. This would result in an expected 50000 deaths per year due to coronary heart disease and strokes that could have been prevented. If it is off by $+5 \mathrm{~mm} \mathrm{Hg}$ at this range, it could cause 27 million people to be inappropriately diagnosed as hypertensive and receive unneeded treatment to the tune of several billions of dollars per year.

Even though the BHS allows for $12 \mathrm{~cm}$ single width cuffs for upper arm circumferences smaller than $50 \mathrm{~cm}$, it still recommends three different cuff lengths. ${ }^{11}$ Healthcare practitioners following their guidelines will therefore still need three different cuffs. When it is a question of having three proportional width cuffs $v s$. three single width cuffs, it is difficult to see any difference in convenience. Either way, the practitioner will have the same number of cuffs on hand. Either way, the practitioner will have to determine the appropriate cuff to use. Without a significant gain in convenience, it is not easy to justify the loss in accuracy that comes with single width cuffs.
In conclusion, these $12 \mathrm{~cm}$ single width blood pressure cuffs could result in a significant number of people being misdiagnosed and mistreated for hypertension. Therefore, to avoid 'cuff hypertension' and 'cuff hypotension,' the cuff width should be proportional to arm circumference.

1 Naqvi NH, Blaufox MD. Blood pressure measurement an illustrated history. Parthenon Pub. Group, New York, 1998, pp 67-82.

2 O'Brien E. Review: a century of confusion; which bladder for accurate blood pressure measurement? J Hum Hypertens 1996; 10: 565-572.

3 Geddes LA. Handbook of Blood Pressure Measurement. Humana Press, Clifton, NJ, 1991, pp 55-61.

4 O'Brien E, Petrie J, Littler WA, de Swiet M, Padfield PL, Altman D, Bland M, Coats A, Atkins N. The British Hypertension Society Protocol for the evaluation of blood pressure measuring devices. J Hypertens 1993; 11(Suppl 2): S43-S63.

5 Geddes LA, Whistler SJ. The error in indirect blood pressure measurement with the incorrect size cuff. Am Heart J 1978; 96: 4-8.

6 Petrie JC, O'Brien ET, Littler WA, de Swiet M. British Hypertension Society. Recommendations on blood pressure measurement. BMJ 1986; 293: 611-615.

7 O'Brien E, Asmar R, Beilin L, Imai Y, Mallion J-M, Mancia G, Mengden T, Myers M, Padfield P, Palatini P, Parati G, Pickering T, Redon J, Staessen J, Stergiou G, Verdechia P. European Society of Hypertension recommendation for conventional, ambulatory and home blood pressure measurement. J Hyperten 2003; 21: 821-848.

8 Association for the Advancement of Medical Instrumentation. American National Standard. Manual, Electronic or Automated Sphygmomanometers ANSI/AAMI SP1O2002/A1. AAMI: 3330 Washington Boulevard, Suite 400, Arlington, VA 22201-4598, USA, 2002.

9 O'Brien E, Pickering T, Asmar R, Myers M, Parati G, Gianfranco S, Staessen J, Mengden T, Imai Y, Waeber B, Palatini P, Gerin W. Working Group on Blood Pressure Monitoring of the European Society of Hypertension. International protocol for validation of blood pressure measuring devices in adults. Blood Press Monit 2002; 7: 3-17.

10 Pickering TG, Hall JE, Appel LJ, Falkner BE, Graves J, Hill MN, Jones DW, Kurtz T, Sheps SG, Roccella EJ. Recommendations for blood pressure measurement in humans and experimental animals: Part 1: blood pressure measurement in humans: a statement for professionals from the Subcommittee of Professional and Public Education of the American Heart Association Council on High Blood Pressure Research. Hypertension 2005; 45: 142-161.

11 Williams B, Poulter NR, Brown MJ, Davis M, Mclnnes GT, Potter JF, Sever PS, Thom S. Guidelines for management of hypertension: report of the fourth working party of the British Hypertension Society, 2004-BHS IV. J Hum Hypertens 2004; 18: $139-185$.

12 O'Brien E, Atkins N, Stergiou G, Karpettas N, Parati G, Asmar R, Imai Y, Wang J, Mengden T, Shennan A. European Society of Hypertension International Protocol revision 2010 for the validation of blood pressure measuring devices in adults. Blood Pressure Monitoring 2010; 15: 23-38.

13 National Institutes of Health. National High Blood Pressure Education Program (NHBPEP)/National Heart, Lung, and Blood Institute (NHLBI) and American Heart Association (AHA): Working Meeting on Blood Pressure Measurement; 2002 Apr 19; Natcher Conference Center. National Institutes of HealthL Bethesda, Maryland, 2002. p.46. 